\title{
Age structural transition in South Africa
}

\author{
P.S. Nair \\ Department of Population Studies, University of Botswana \\ nairps@mopipi.ub.bw
}

\section{Abstract}

This chapter deals with the current age structure and the age structural transition (AST) underway in South Africa. We have used the national Census data for 1996 and 200 I and the Community survey data for 2007. In 2007, 3 I percent of the population was enumerated below 15 years of age, 64 percent between 15 64 and 5.4 percent $65+$ implying the early stages of aging process. The median age in 2007 is 24.3 years, increased from 23 years in 1996. The proportion of young dependents is declining whereas that of the economically active and aged populations are increasing. Generally, the Black population appears younger and the Whites older. The other two ethnic groups are placed in the middle. This is, perhaps, a reflection of the differential fertility across the ethnic groups. The proportion of labour force population in 2007 is the highest for Asians \& Indians followed by Whites; and the lowest for Blacks. So far as the proportion of the aged is concerned, Whites lead relatively high (I2.4\%) as compared to coloured and Black population groups.

During 1996-2007, the age structural transition for the total population is only marginal in South Africa. The median age of the total population grew from 23 years to 24.3 years, an increase of 5.6 percent. The female median age grew from 24.5 to 25.2 years, slightly better than that of males. The old age population has increased by 12.5 percent during the same period along with the global trend of female advantage. Again, the labour force population has increased by 5.5 percent. AST is highest for the white population, followed closely by Asians \& Indians. This calls for continued higher investments in primary and secondary education, health care service delivery including reproductive health and social security. Again, for a country like South Africa where unemployment is quite high, the enormity of labour force (64\%) has to be viewed seriously. Rapid employment generation, especially for the weaker groups, is the key. Further, one fifth (20.4 $\%)$ of the population is in the 15-24 years age group which is the target group for tertiary education. The slow process of AST among Black population warrants for preferential resource allocations especially in the areas of reproductive health and employment.

\section{Introduction}

While high fertility and declining mortality were the leading demographics of the $20^{\text {th }}$ century, no doubt low fertility and population aging are the dominant demographic issues of the $21^{\text {st }}$ century.
In 1950, only 5 percent of the world population was aged $65+$; at the beginning of the $21^{\text {st }}$ century, the proportion reached 7 percent. The wide-ranging consequences of population aging are of mounting concern and significance for more developed countries as well as for 
less developed countries. In most industrialized countries, there is a growing concern in areas such as employment, economic growth, health care service delivery, retirement, pensions and social support system. Changing birth cohort sizes because of falling fertility and the reduction of mortality among the old lead to age structural transition (AST). However, in some countries, especially in sub-Saharan Africa, migration and age-specific mortality trends, especially those due to HIV/AIDS, can also affect cohort sizes (Nair, 2007, 20 I0; Nair and Majelantle, 2005). As the countries proceed through their ASTs, every region except Europe will still continue to grow. In Africa, both natural increase and 'momentum effects' will drive this growth for at least two decades (Nair, 2010).

The consequences of AST are more pronounced among youth and labour force populations in developing countries. There is growing concern about the increasing 'youth bulge' in developing countries as an inevitable outcome of AST. The bulge usually occurs in countries in the early stages of their demographic transition where although fertility remains high, infant and child mortality has begun to fall paving the way for more children to survive. Population economists have long recognized this youth bulge as a 'demographic bonus' or 'window of opportunity' to economic growth when productivity, savings, and taxes of young people support smaller populations of children and elderly. During the period of the window of opportunity, social sector expenditures are reduced due to lesser demand for health care services by the smaller young and old aged populations as well as reduced demand for educational services due to declines in the growth of school-aged population. Therefore, the demographic bonus is likely to contribute partly to the growth of the national economy if favourable and adequate policies are pursued.

With this backdrop, this paper deals with the current age structure and the age structural transition (AST) in South Africa since 1996. For the analysis, the total population by sex, provinces and ethnic groups are considered. We have used the national Census data for 1996 and $200 \mathrm{I}$ and the Community survey data for 2007. Age structure of a population is the product of the changes in the three components of population dynamics, namely fertility, mortality and migration over a sufficiently long period of time. Analysis of the information on the age structural transition (AST) over the years provides us the knowledge on changing dependency ratios, changes in labour force and more importantly the prospects of population aging. Apart from its role in explaining the current scenarios of socio-economic needs, it is vital in the context of integrating population variables into development planning especially for developing economies.

\section{Age structure}

Table I presents the age distribution of South African population from 1996 through 2007 in five year age groups. In 2007, 3 I percent of the population was enumerated below 15 years of age, 64 percent between 15-64 and 5.4 percent aged. The proportion of aged, slightly above 5 percent, implies that the South African population is in the 
early stages of an aging process. It is not young or old, but a mature one as per UN classification. The median age in 2007 is 24.3 years, increased from 23 years in 1996. The trend from 1996 shows that the population is in the process of aging, but rather slowly. The proportion of young dependents is declining; of the economically active and aged populations increasing. Simi- larly, the young age dependency ratio also has declined from 56 percent in 1996 to 48.8 percent in 2007. Consequently, the old age dependency ratio has increased slightly, from 7.9 to 8.5 percent during the same period while the total dependency ratio has declined slightly, over the years, from 64 to 57 percent.

Table I Age distribution (total population) of South Africa, 1996, $200 \mathrm{I}$ and 2007.

\begin{tabular}{|c|c|c|c|}
\hline Age & 1996 & 2001 & 2007 \\
\hline $0-4$ & 10.7 & 10.09 & 10.28 \\
\hline $5-9$ & 11.54 & 11.14 & 10.55 \\
\hline $9-14$ & 11.5 & 11.63 & 10.2 \\
\hline $15-19$ & 10.33 & 11.35 & 10.5 \\
\hline $20-24$ & 9.84 & 9.54 & 9.88 \\
\hline $25-29$ & 8.54 & 8.6 & 8.38 \\
\hline $30-34$ & 7.6 & 7.26 & 7.7I \\
\hline $35-39$ & 6.56 & 6.68 & 6.63 \\
\hline $40-44$ & 5.29 & 5.67 & 5.85 \\
\hline $45-49$ & 4.15 & 4.53 & 4.97 \\
\hline $50-54$ & 3.14 & 3.56 & 4.06 \\
\hline $55-59$ & 2.64 & 2.62 & 3.23 \\
\hline $60-64$ & 2.2 & 2.34 & 2.39 \\
\hline $65-69$ & 1.88 & 1.75 & 1.98 \\
\hline $70-74$ & 1.19 & 1.44 & 1.37 \\
\hline $75-79$ & 0.93 & 0.82 & 0.99 \\
\hline $80-84$ & 0.44 & 0.63 & 0.54 \\
\hline $85+$ & 0.34 & 0.35 & 0.5 \\
\hline Total & 100.00 & 100.00 & 100.00 \\
\hline Median Age & 23.01 & 22.55 & 24.29 \\
\hline TDR (\%) & 63.89 & 60.90 & 57.25 \\
\hline YDR (\%) & 55.96 & 52.87 & 48.79 \\
\hline ODR (\%) & 7.93 & 8.03 & 8.46 \\
\hline
\end{tabular}

TDR=Total Dependency Ratio, YDR= Young Dependency Ratio. ODR= Old Age Dependency Ratio 
2.2 Age-sex structure

As we observe from Table 2, the female population is older than their counterparts in all the three time points. The median ages of females have always been I-2 years higher than that of males.

Table 2 Age-sex structure of population, South Africa, 1996-2007.

\begin{tabular}{|c|c|c|c|c|c|c|}
\hline \multirow{2}{*}{ Age } & \multicolumn{2}{|c|}{1996} & \multicolumn{2}{|c|}{2001} & \multicolumn{2}{|c|}{2007} \\
\hline & Male & Female & Male & Female & Male & Female \\
\hline $0-4$ & 10.9 & 10.64 & 10.37 & 9.52 & 10.69 & 9.89 \\
\hline $5-9$ & 12.1 & 11.15 & 11.32 & 10.39 & 10.95 & 10.17 \\
\hline $10-14$ & 11.97 & 11.2 & 11.75 & 10.88 & 10.49 & 9.93 \\
\hline $5-19$ & 10.64 & 10.18 & 11.44 & 10.82 & 10.93 & 10.1 \\
\hline $20-24$ & 9.96 & 9.86 & 9.79 & 9.39 & 10.13 & 9.65 \\
\hline $25-29$ & 8.64 & 8.57 & 8.86 & 8.71 & 8.72 & 8.06 \\
\hline $30-34$ & 7.61 & 7.7I & 7.44 & 7.47 & 8.05 & 7.39 \\
\hline $35-39$ & 6.69 & 6.56 & 6.73 & 6.97 & 6.63 & 6.63 \\
\hline $40-44$ & 5.38 & 5.32 & 5.76 & 5.93 & 5.6 & 6.08 \\
\hline $45-49$ & 4.27 & 4.16 & 4.51 & 4.79 & 4.74 & 5.18 \\
\hline $50-54$ & 3.17 & 3.24 & 3.59 & 3.72 & 3.81 & 4.29 \\
\hline $55-59$ & 2.57 & 2.83 & 2.58 & 2.79 & 3.04 & 3.41 \\
\hline $60-64$ & 1.89 & 2.62 & 2.07 & 2.66 & 2.11 & 2.65 \\
\hline $65-69$ & 1.64 & 2.22 & 1.42 & 2.07 & 1.69 & 2.26 \\
\hline $70-74$ & 1.08 & 1.43 & 1.08 & I.7I & 1.03 & 1.69 \\
\hline $75-79$ & 0.8 & 1.18 & 0.64 & 0.99 & 0.7 & 1.26 \\
\hline $80-84$ & 0.39 & 0.62 & 0.42 & 0.77 & 0.37 & 0.7 \\
\hline $85+$ & 0.3 & 0.51 & 0.21 & 0.43 & 0.3 & 0.68 \\
\hline Total & 100 & 100 & 100 & 100 & 100 & 100 \\
\hline Median & 22.20 & 23.46 & 22.61 & 24.47 & 23.43 & 25.16 \\
\hline Sex Ratio & \multicolumn{2}{|c|}{921} & \multicolumn{2}{|c|}{917} & \multicolumn{2}{|c|}{933} \\
\hline
\end{tabular}

The sex ratio has always been favourable to females. However, there is an increase of 12 points for the sex ratio from 1996 to 2007 . In 2007, it stood at 933 males per 1000 females.

\section{I 2 Population pyramids}

A population pyramid gives not only a graphic snapshot of the age-sex structure, but it is also capable of examining the demographic history of a country. Figures 2, 3 and 4 depict the age structures of 1996, 200 I and 2007 in population pyramids. Figure 5 provides an instant comparison of the three age 
structures in one pyramid.

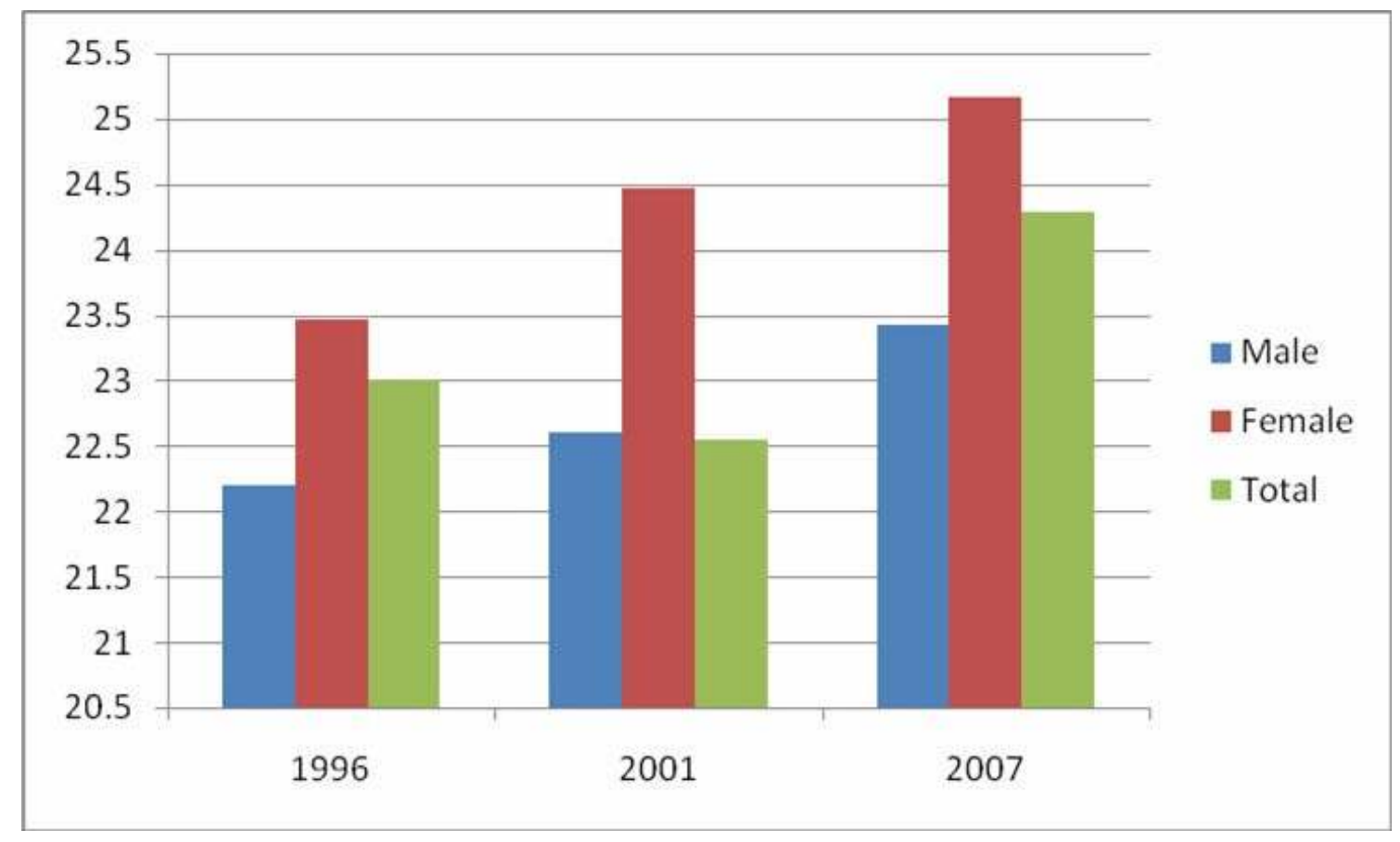

Figure I Median ages - male, female and total populations - I996-2007.

A comparison of the three pyramids reveals the following. The shape of all pyramids is atypical of high fertility and mortality and a lesser degree of age structural transition. Whatever transition is occurring, it is from the bottom of the pyramid; not at the top. The base population (0-9 years) is shrinking which is indicative of recent declines in fertility in South Africa. Again, there appears to be a disproportionate growth of population between males and females ; male population growing a little faster than females especially in the age groups above 10 years in recent years.

\subsection{Ethnic groups}

South Africa represents a rich array of ethnic backgrounds which became highly volatile during the apartheid era, when the government used it for political and racial purposes. The government established language or ethnic areas and, during the 1950s and 1960s, assigned them separate residential areas according to perceived ethnic identity. Apartheid policies also empowered the government to remove black South African townships that were created, legally and illegally, around the cities. Also, the repressive policies led to severe backwardness and gross neglect, socially and economically, among non-whites, especially Blacks. 


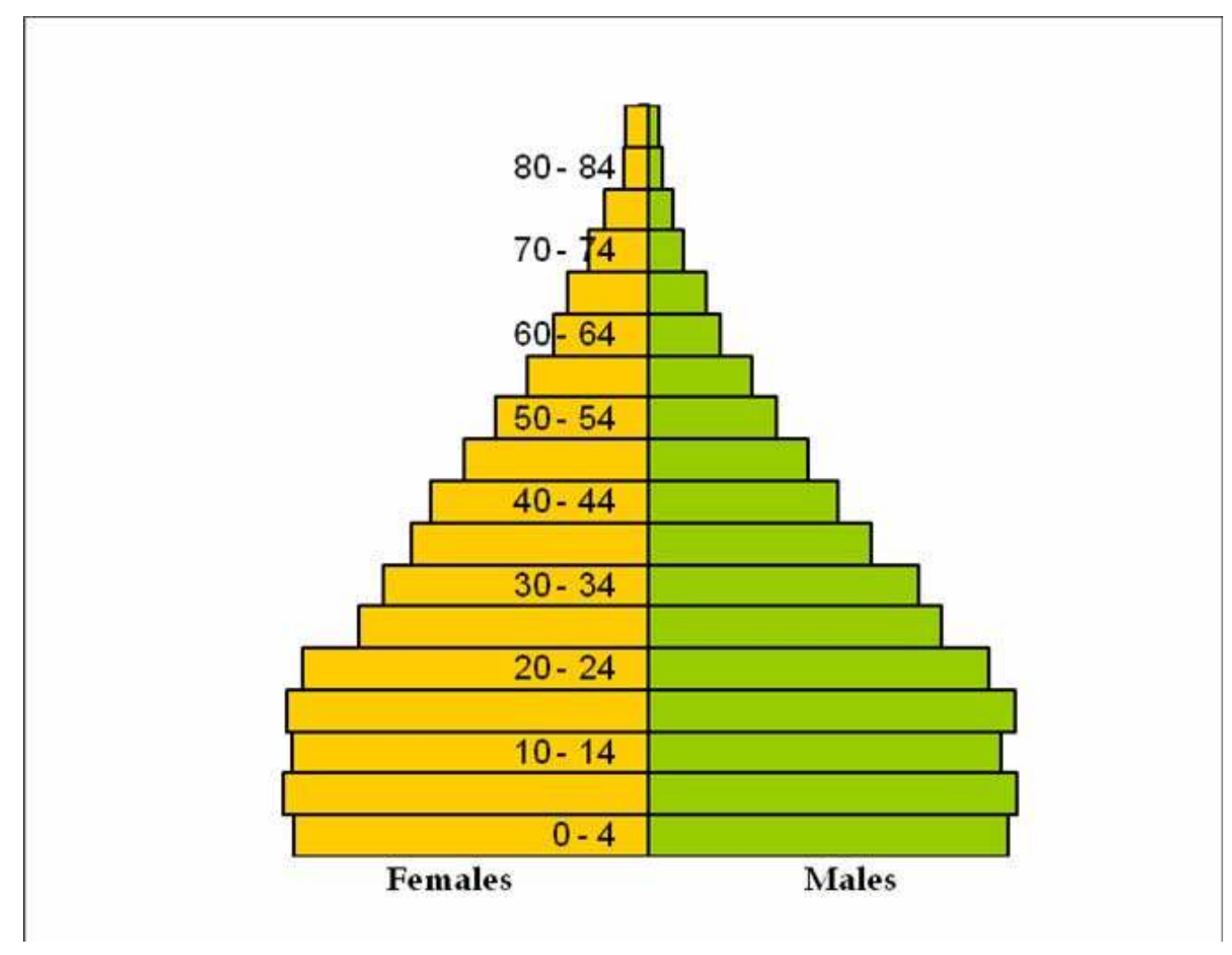

Figure 2 Age-sex pyramid, South Africa, 2007

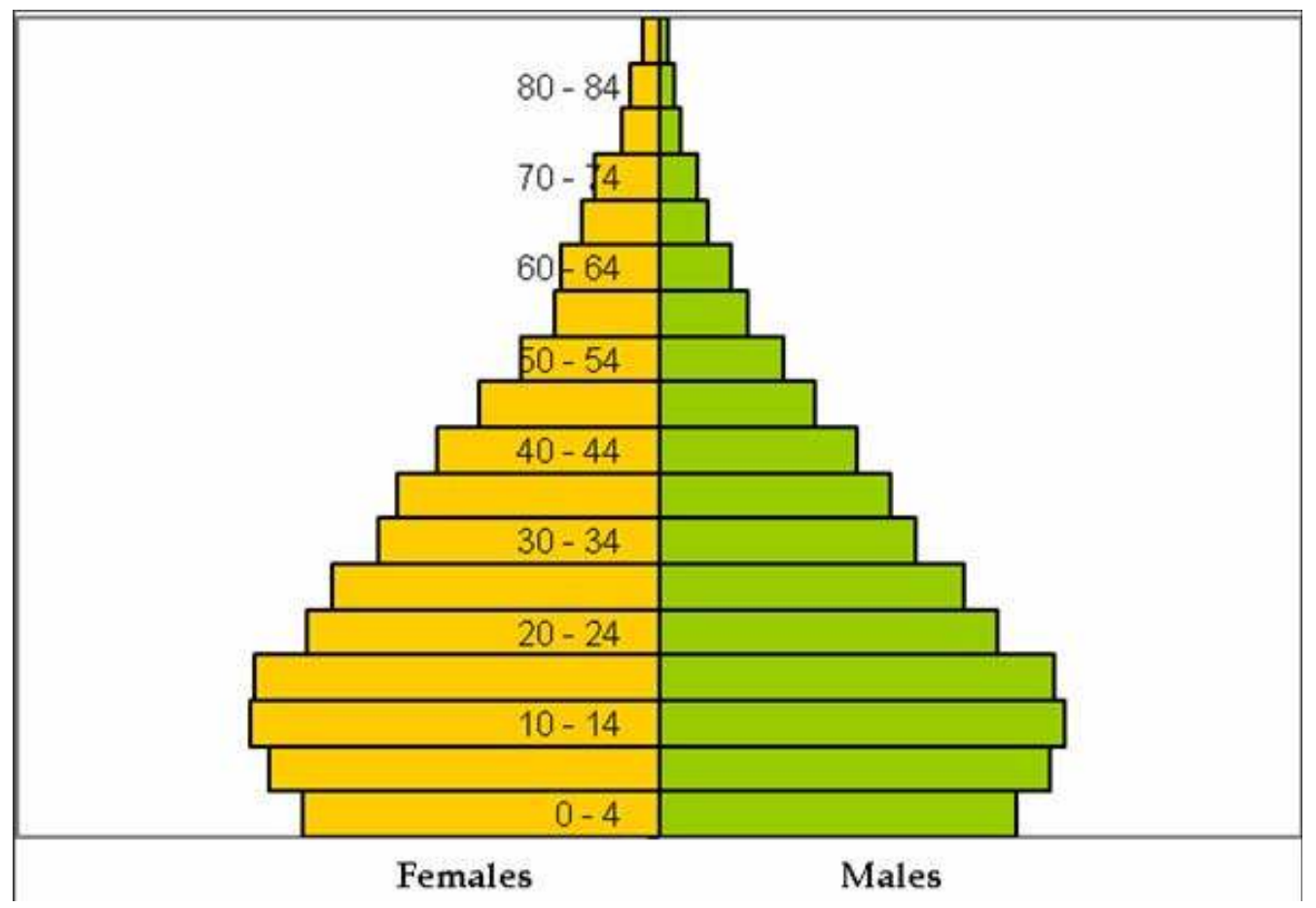

Figure 3 Age-sex pyramid, South Africa, $200 \mathrm{I}$. 


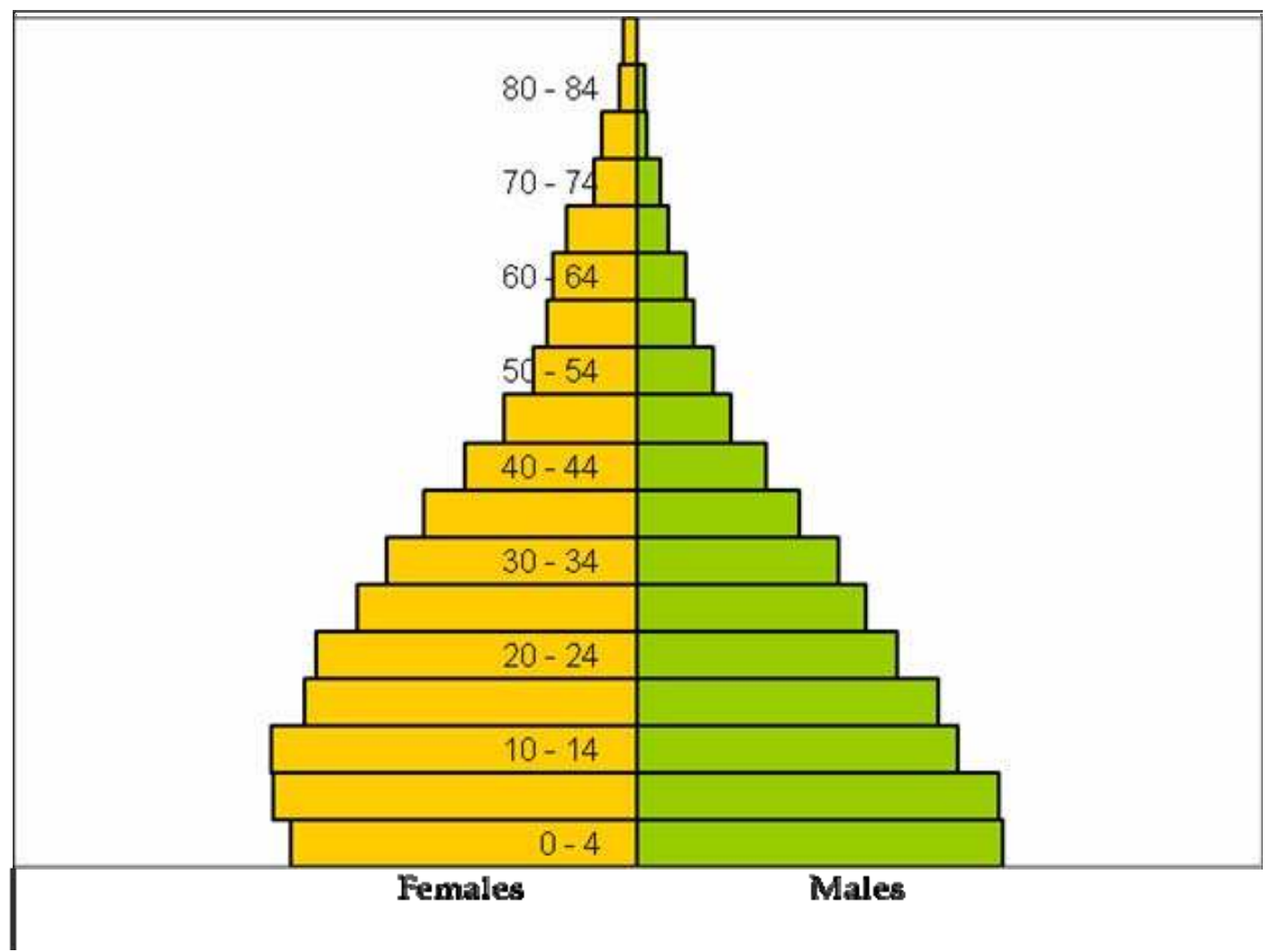

Figure 4 Age-sex pyramid, South Africa, 1996.

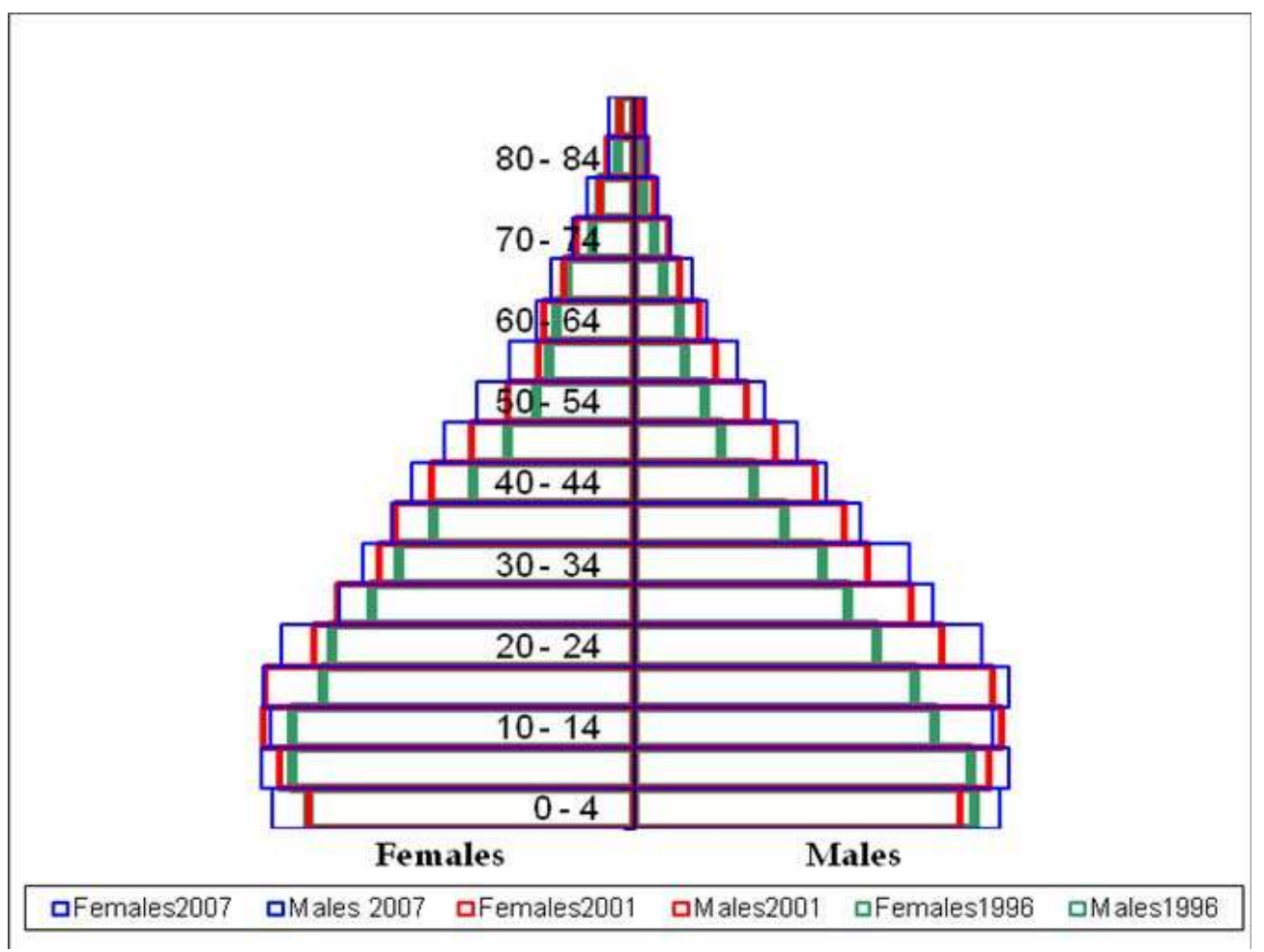

Figure 5 Age-sex pyramid, South Africa, 1996, 200I \& 2007 
In 1993 and 1994, as the country emerged from the apartheid era, many South Africans appeared to reclaim their ethnic heritage and to acknowledge pride in their ancestry. The new political leaders recognized the practical advantage of encouraging people to identify both with the nation and with a community that had a past older than the nation. So, the interim constitution of 1993 reaffirmed the importance of ethnicity by elevating nine African languages to the status of official languages of the nation, along with English and Afrikaans. Thus, Ethnic groups play a crucial role in the socio-economic and political scenario of South Africa, perhaps better than in any other subSaharan country (http://countrystudies.us/south-africa/45.htm).

Generally, the Black population appears younger and the Whites older. The other two ethnic groups are placed in the middle. This is, perhaps, a reflection of the differential fertility across the ethnic groups. Whites experienced a long and sustained fertility decline from the end of the 19th century until attaining below-replacement fertility by 1989, with a TFR of I,9 (Chimere-Dan, O, 1993). Asian fertility also declined steadily, from a TFR of about 6 in the 1950s to 2,7 in the late 1980s. Coloured fertility declined remarkably rapidly from 6,5 in the late 1960s to about 3 by the late 1980s. African ( Black) fertility is estimated to have decreased from a high of 6,8 to a low of about 3,9 between the mid-1950s and the early 1990s. Although it continues declining, Black's fertility is still substantially higher than that of the other racial groups (Swartz, n.d). As fertility declines, the youth cohorts get shrunk and gradually adult and aged cohorts get increased, although mortality exerts opposing effect to a limited extent.

For instance, in 2007, the median age was the highest for Whites (38 years) compared to 23 years for Blacks. In line with the general population, the median ages all ethnic groups have been rising over the years. The proportion of young dependents ( 0 - 14 years) is again the lowest for Whites followed by Asians and Indians and for Blacks, it is quite high, around one third of the population. Interestingly, the proportion of economically active population in 2007 is the highest for Asians and Indians followed by Whites; and the lowest for Blacks. For the whole population, it ranges from 62 to 72 percent. So far as the proportion of the aged segment of the population is concerned, Whites lead relatively high (12.4\%) as compared to coloured and Black population groups. These imply that the white population is quite aged in relation to other three ethnic groups in South Africa - a reflection of lower fertility, lower mortality and higher economic status. The dependency rates are also higher for Black population and lesser for Whites and Asians \& Indians. 


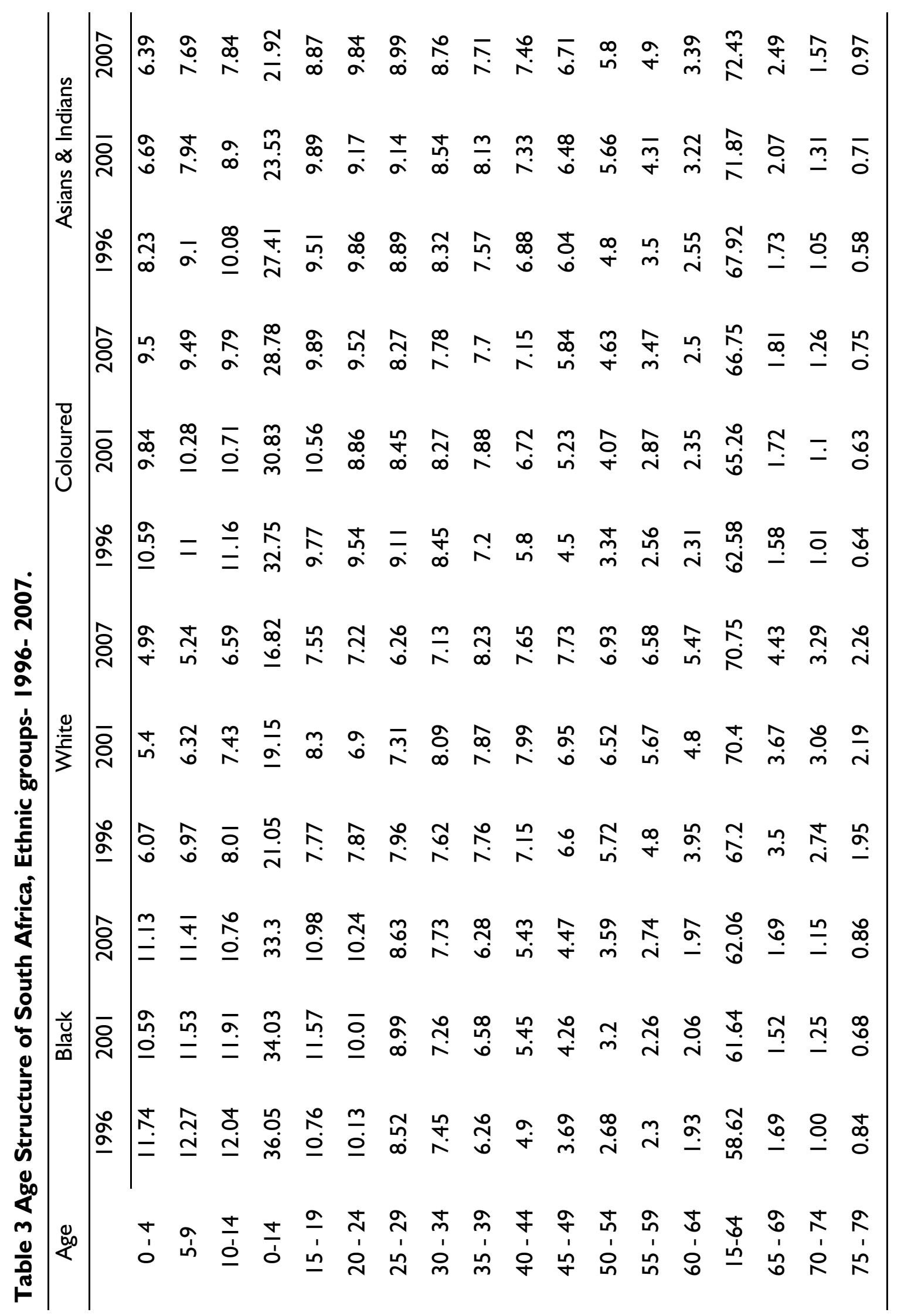


African Population Studies Vol 25, 2 (Dec 20II)

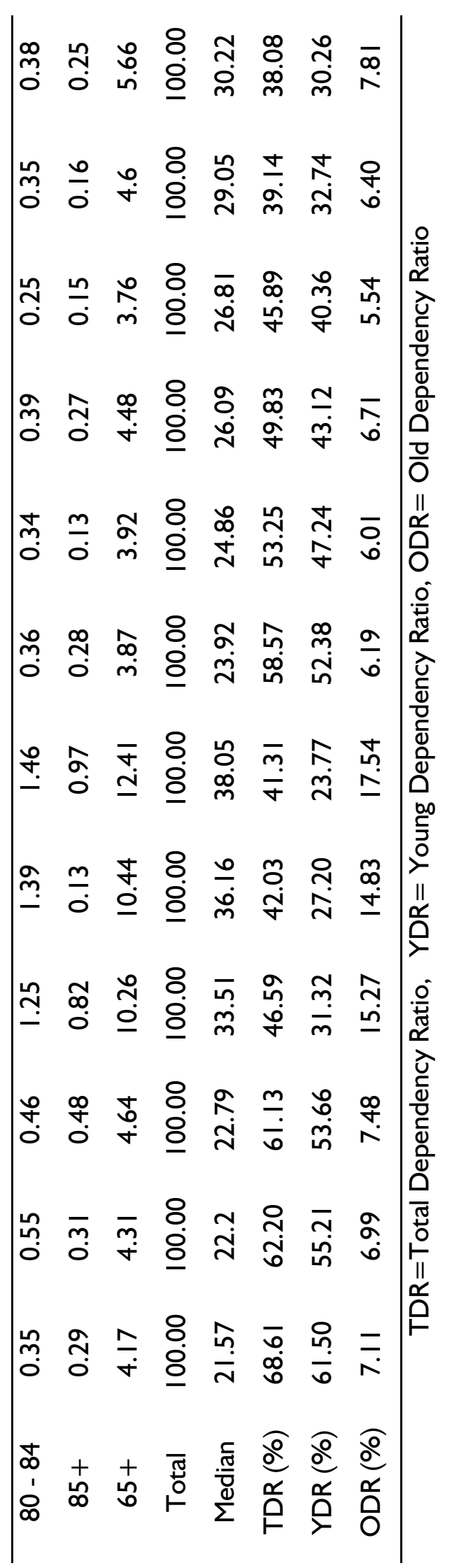




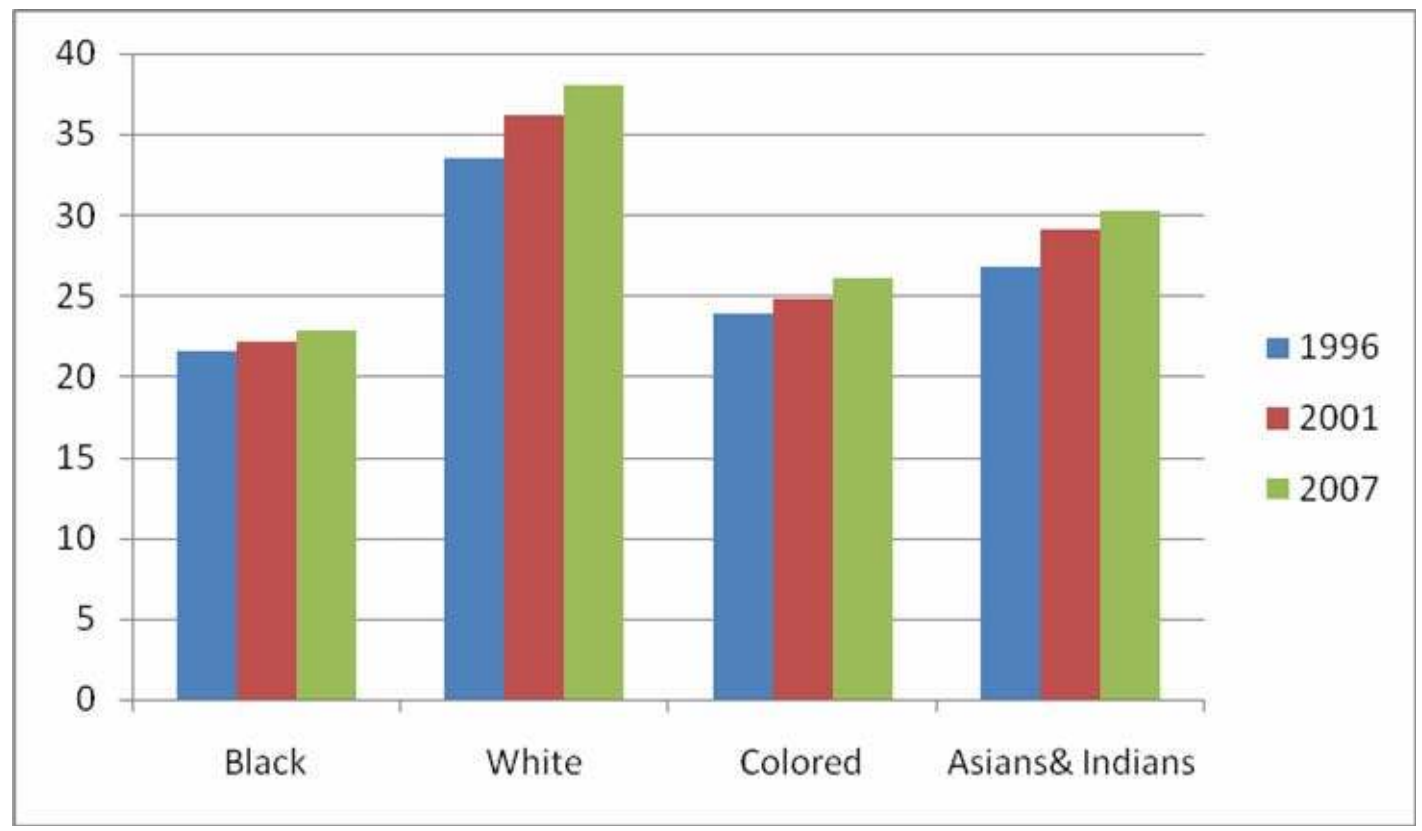

Figure 6 Median ages, ethnic groups, 1996-2007.

\subsection{Provincial populations}

The age structure of the nine provincial populations is presented in Table 4 below. In 2007, Gauteng has the highest Median age (28.2 years) and Limpopo the lowest (20.1 years). Except Western Cape, all other districts showed sustained increase in the median ages reflecting the impact of declining fertility and mortality.

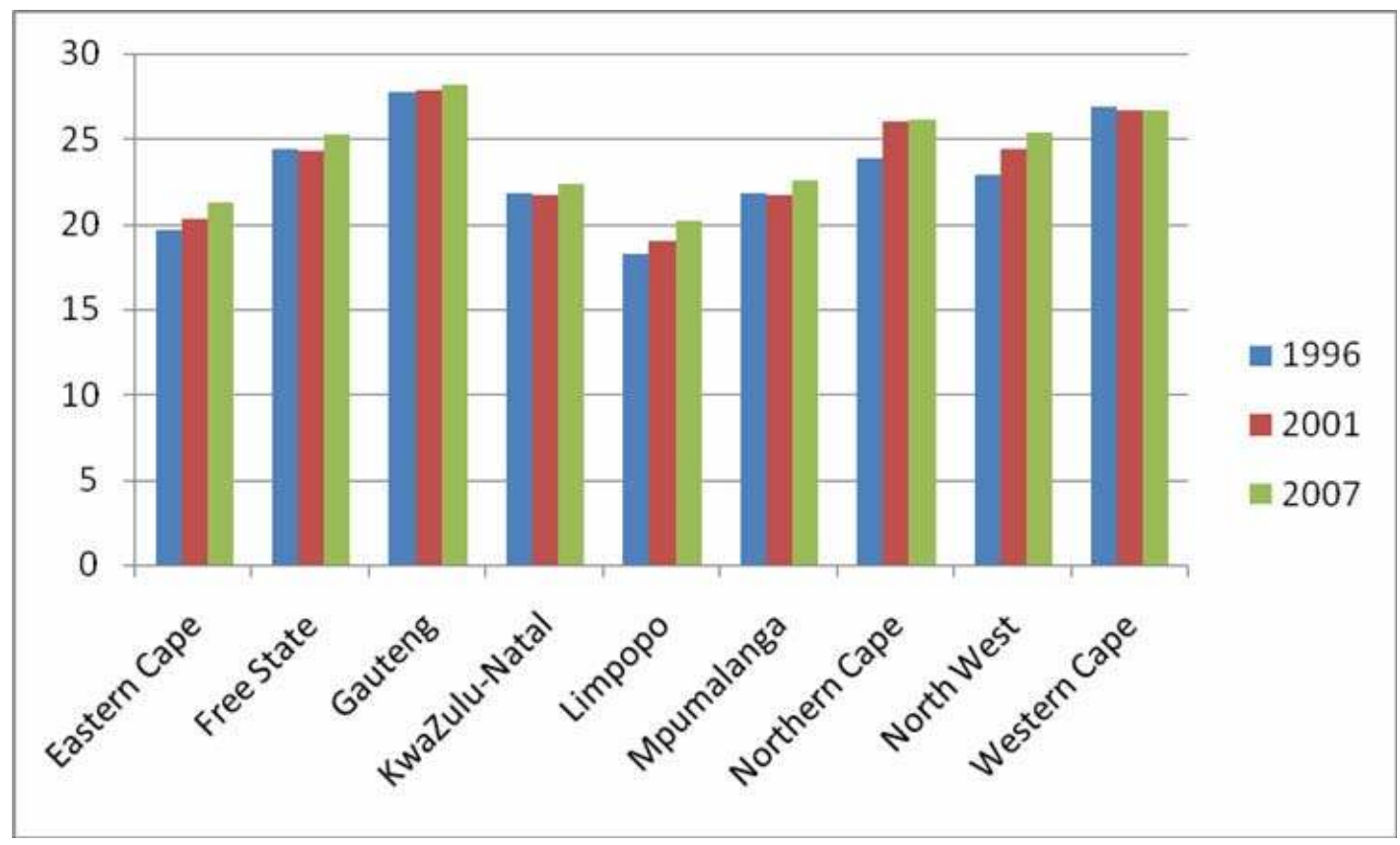

Figure 7 Median ages, provinces, 1996-2007. 


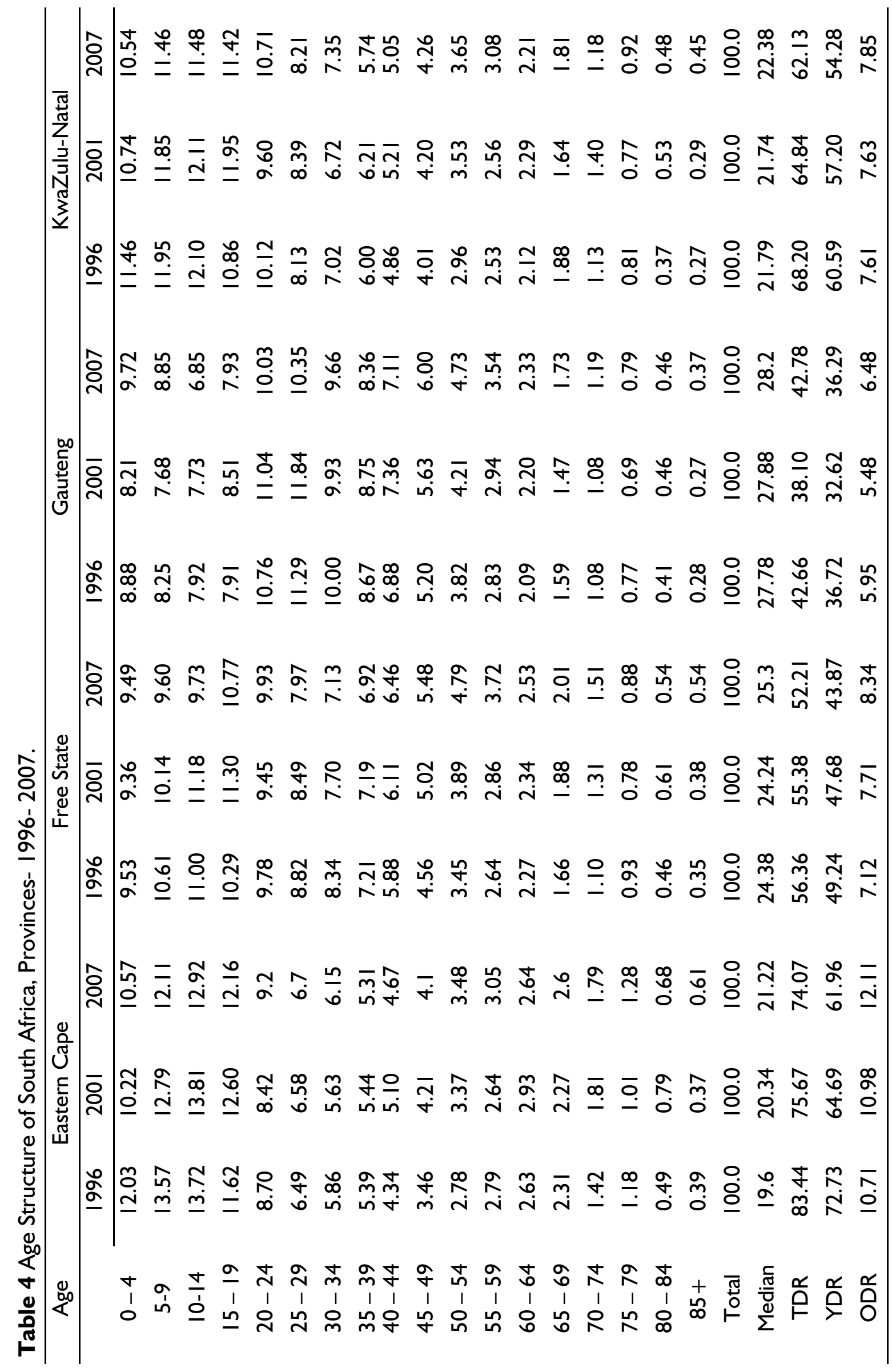




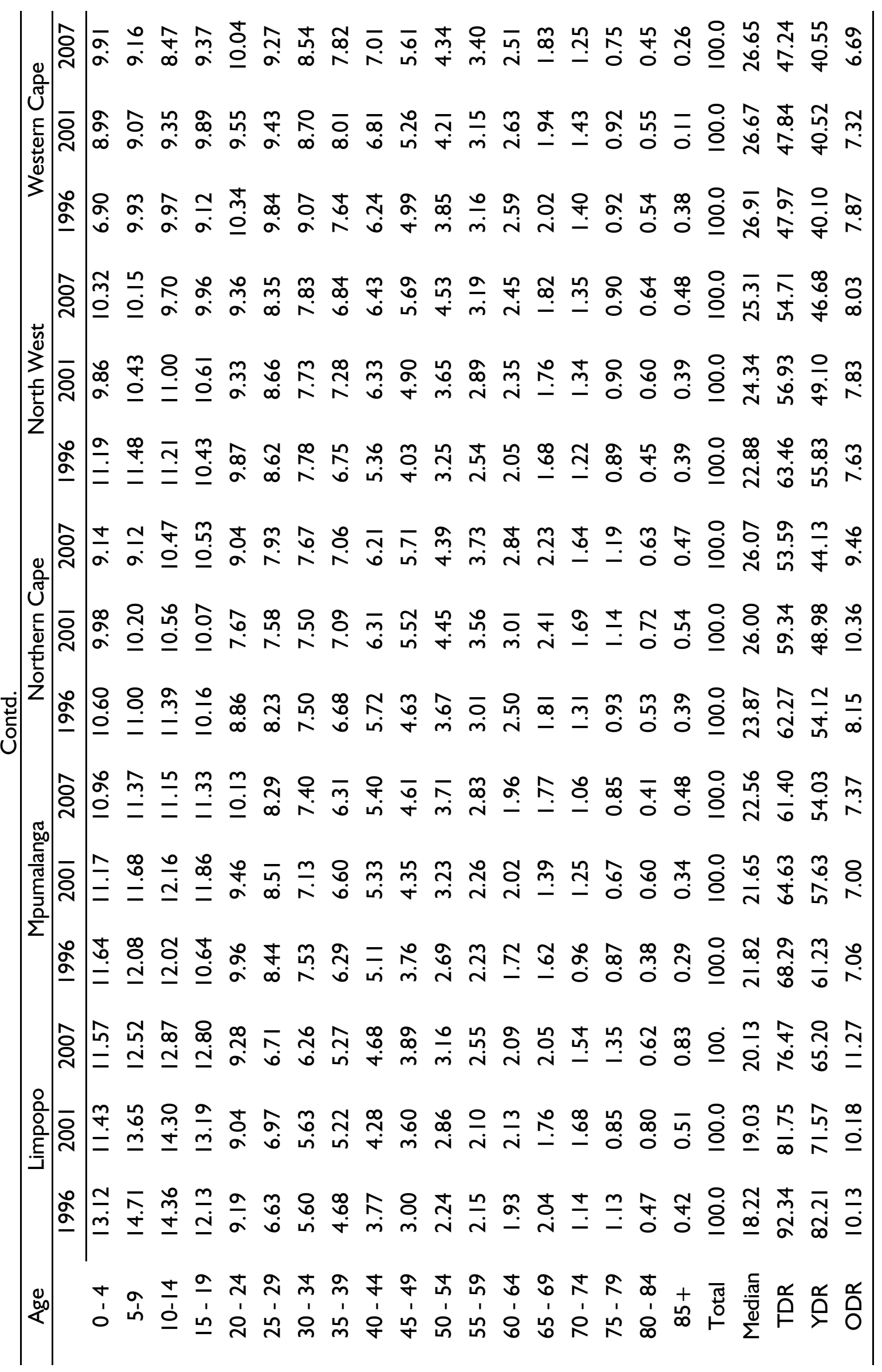




\section{Age structural transition}

Although the period under study is rather short (1996-2007), it is hoped that an analysis of AST is a worthwhile attempt to throw some light on its impact on the economy in terms of development needs and other policy issues looming the country. For the sake of analytical convenience, only three broad age groups are considered here, viz. 0-14 years, 15-64 years and $65+$ years.

\subsection{Total population}

During 1996-2007, the age structural transition (AST) for the total population is only marginal in South Africa. The median age of the total population grew from 23 years to 24.3 years, an increase of 5.6 percent. The female median age grew from 24.5 to 25.2 years, slightly better than of males. If we examine the transition of broad age groups, the young age population (0-14 years) has declined by 8 per cent for the total population; with a slightly more reduction of female children. The old age population has increased by 12.5 percent during the same period along with the global trend of female advantage. Again, the labour force population has increased by 5.5 percent.

Table 5 Age Structure of (broad age groups), male, female and total populations, 1996 2007.

\begin{tabular}{cccccccccc}
\hline Age & \multicolumn{3}{c}{ Male } & \multicolumn{3}{c}{ Female } & \multicolumn{3}{c}{ Total } \\
\hline & 1996 & 2001 & 2007 & 1996 & 2001 & 2007 & 1996 & 2001 & 2007 \\
$0-14$ & 34.97 & 33.44 & 32.13 & 32.99 & 30.79 & 29.99 & 33.74 & 32.86 & 31.03 \\
$15-64$ & 60.82 & 62.77 & 63.76 & 61.05 & 63.25 & 63.44 & 60.29 & 62.15 & 63.6 \\
$65+$ & 4.21 & 3.77 & 4.09 & 5.96 & 5.97 & 6.59 & 4.78 & 4.99 & 5.38 \\
\hline
\end{tabular}

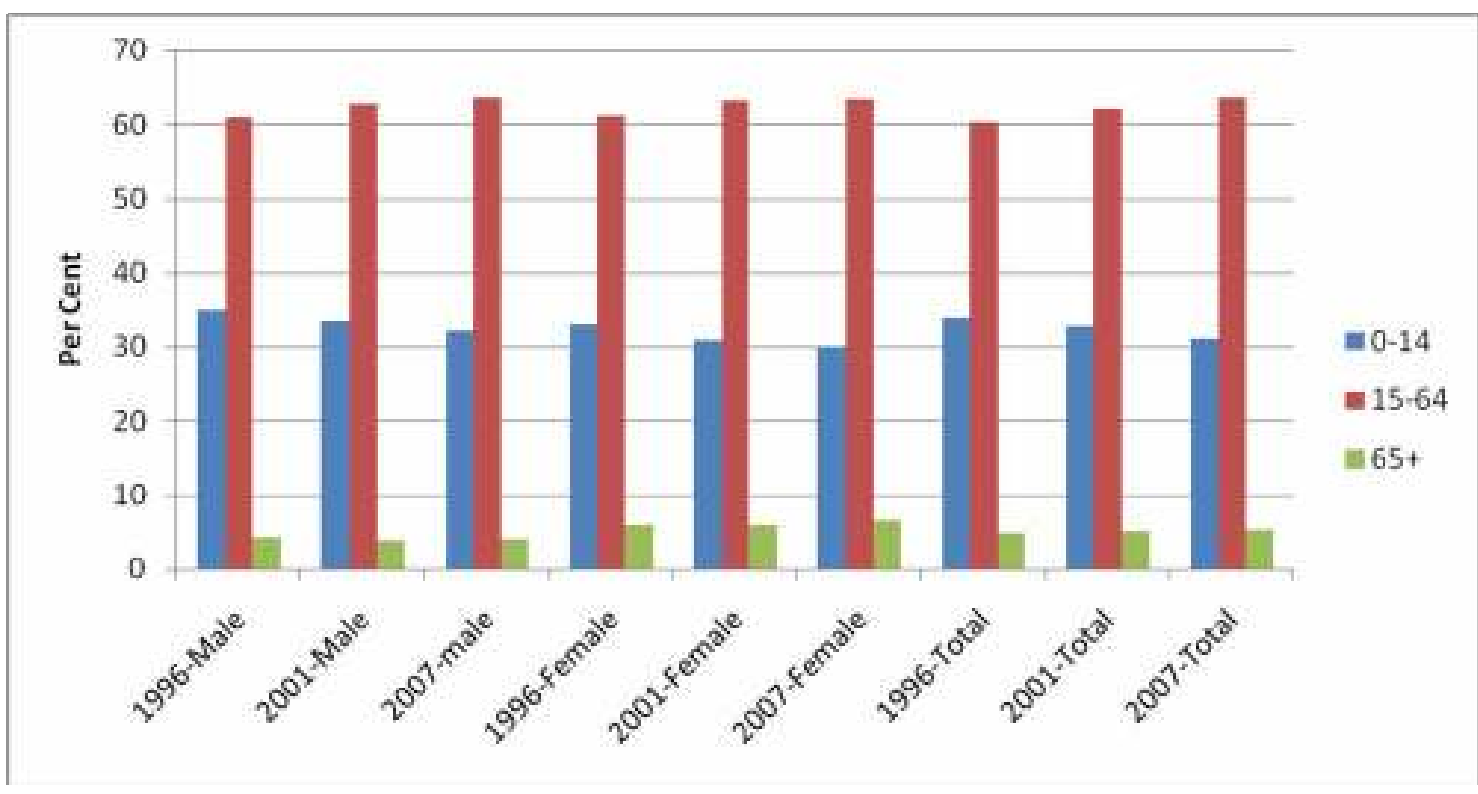

Figure 8 Age Structural Transition, male, female and total population, 1996- 2007. 


\subsection{Ethnic groups}

During 1996-2007, as judged from the increase in median ages, age structural transition is highest for the white population, followed closely by Asians \& Indians. It is the lowest for the Black population. There is 13.5 percent increase in the median age for White population, followed by 12.7 percent increase for Asians and Indians. For coloured and Black population groups, those are 9.1 percent and 5.7 percent respectively. Obviously, the same trend is reflected in the transition of broad age groups as well. The young age population of 0-14 years has declined almost in the same magnitude (20\%) for Whites and Asians \& Indians. The decline is the least for the Blacks $(7.6 \%)$ and the Coloured is placed in the middle (12.1\%). As expected, the aged population has been increasing proportionately. The increase is the highest for Asians \& Indians (50.5\%) followed by Whites $(20.9 \%)$ and Coloured population (15.8\%).

\subsection{Provinces}

In terms of the changes in the median age of population, North West, Limpopo and Eastern Cape provinces registered significant increases. The median age has increased by 10.5 per cent in the first two provinces and by 8.3 percent in the latter province. Interestingly, Western Cape has shown a slight reduction in the median age. In all other districts, the median age grew in the range of $I .5$ to 3.8 percent.

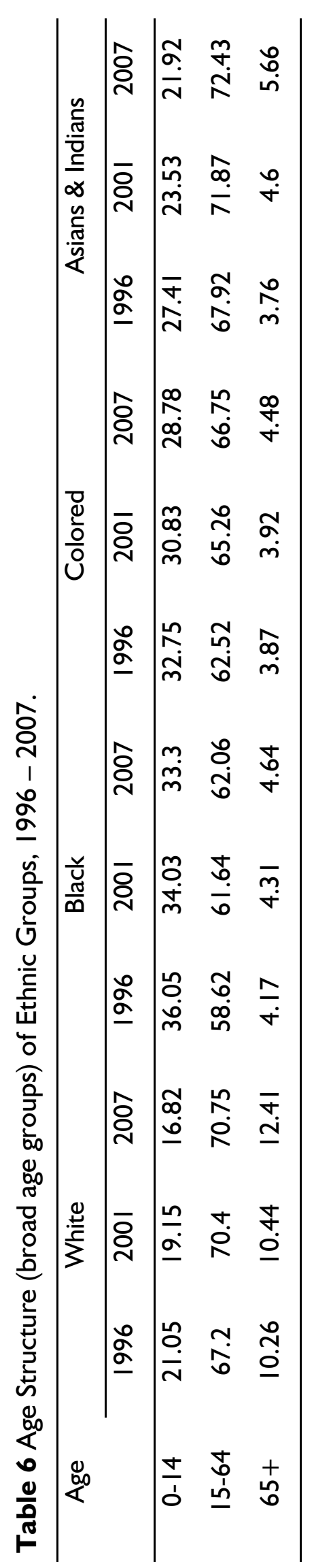




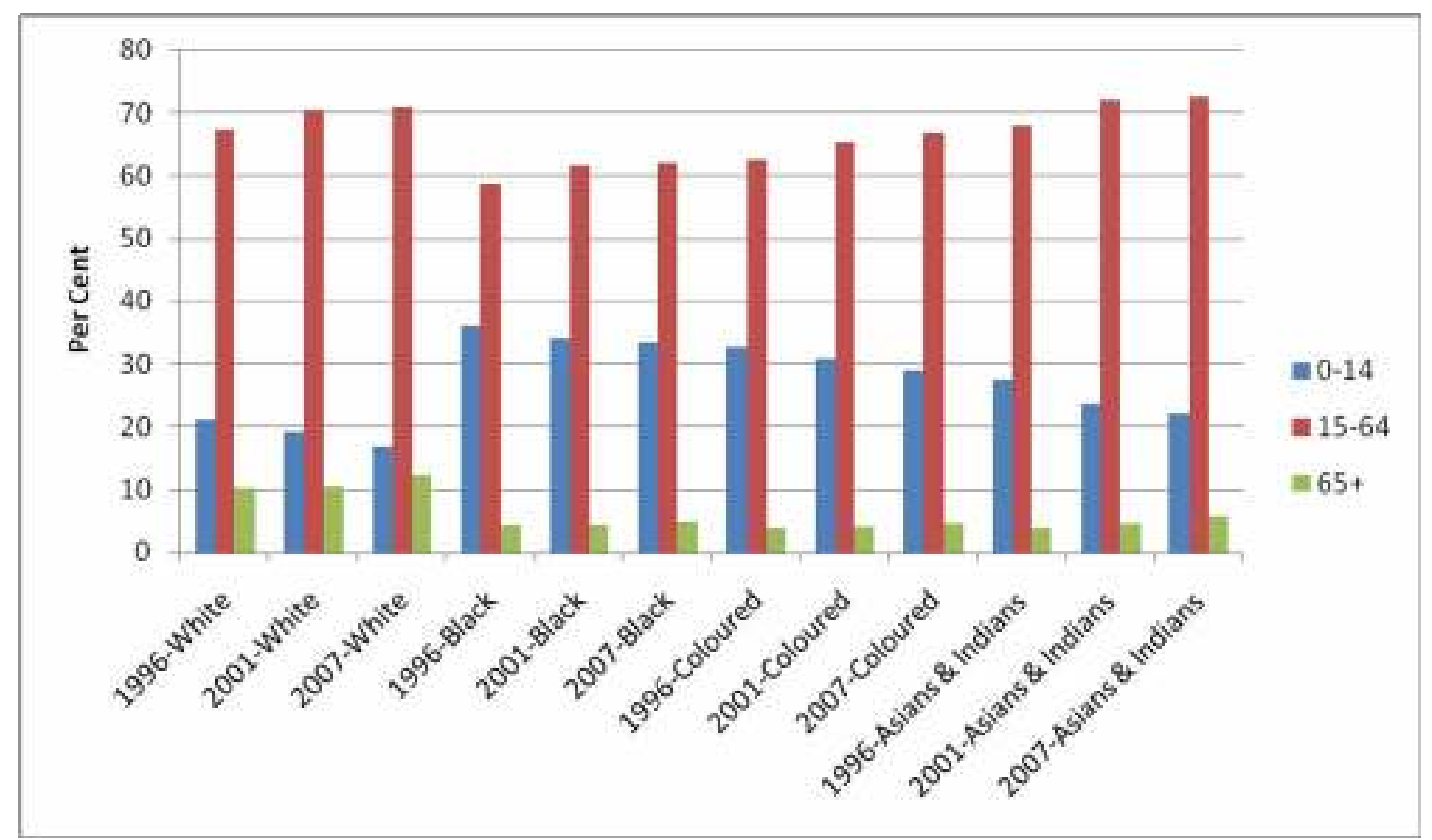

Figure 9 Age Structural Transition of ethnic groups, $1996-2007$.

Comparatively, Northern Cape registered the highest (I $2.9 \%)$ reduction in $0-14$ age group followed by Limpopo (I2.3\%). Surprisingly, there is a slight increase observed in the Western Cape. Gauteng had the lowest increase $(0.3 \%)$. Considerable increase is observed in the old age group (65+) across most of the provinces. Northern Cape registered the highest increase
(23\%) followed closely by Limpopo $(22.8 \%)$, Free State $(21.8 \%)$ and Eastern Cape (20.2\%). Again, in the Western Cape, a slight reduction is observed. The proportion of economically active population has shown only a small increase in the range of $\mathrm{I}-10$ percent. Limpopo has experienced the highest increase of 10.5 percent in this regard. 


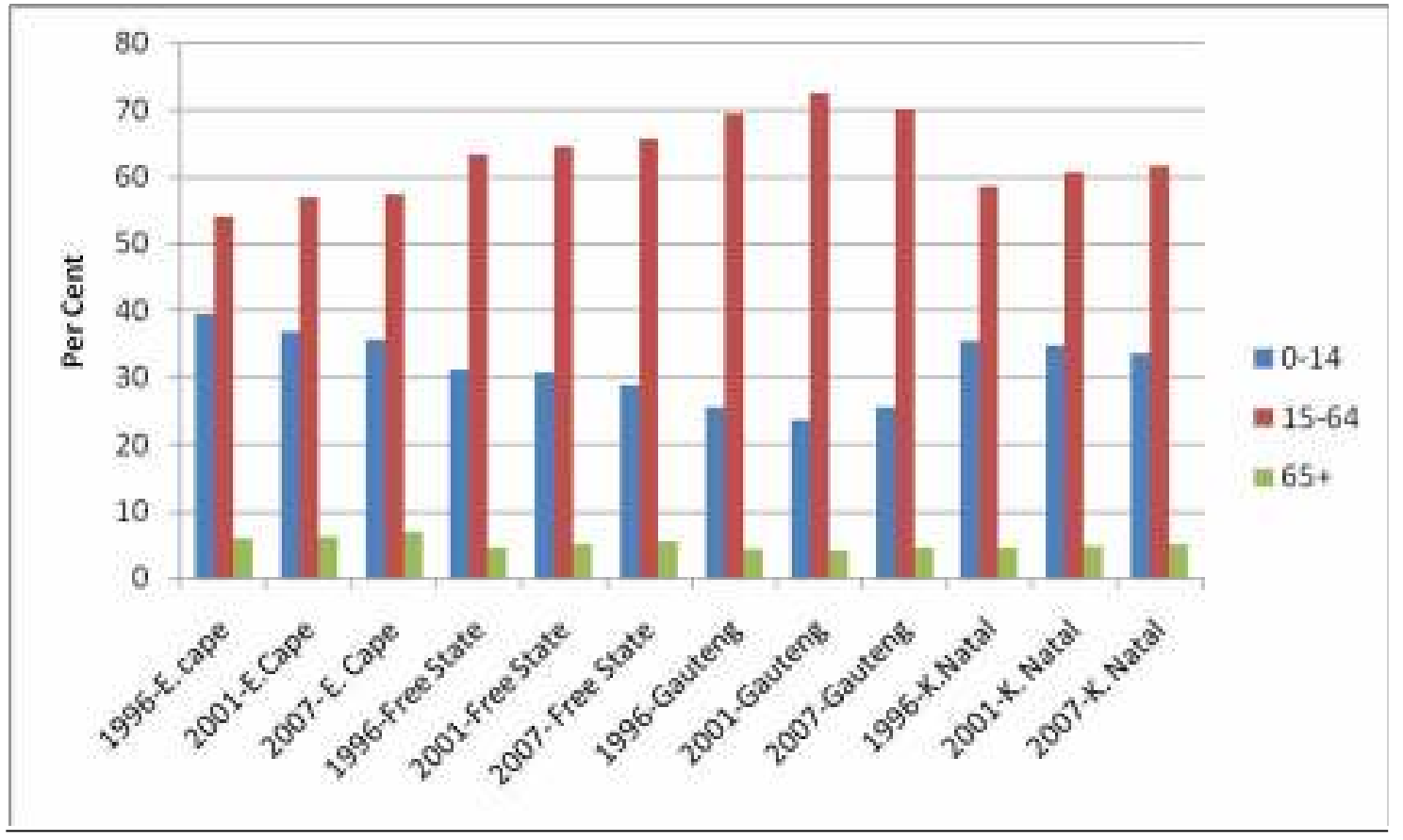

\section{Contd.}

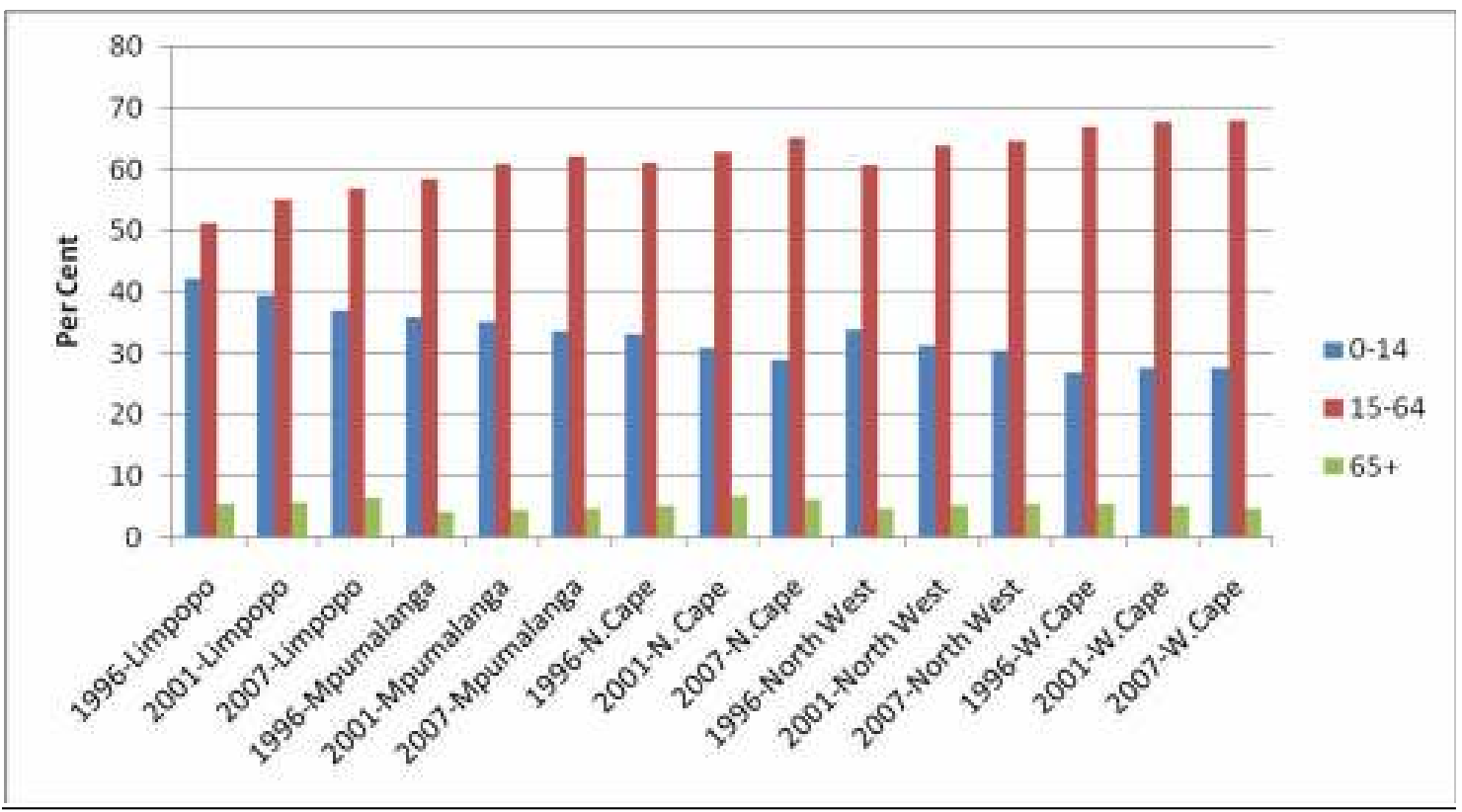

Figure 10 Age Structural Transition of provinces, $1996-2007$. 
African Population Studies Vol 25, 2 (Dec 20II)
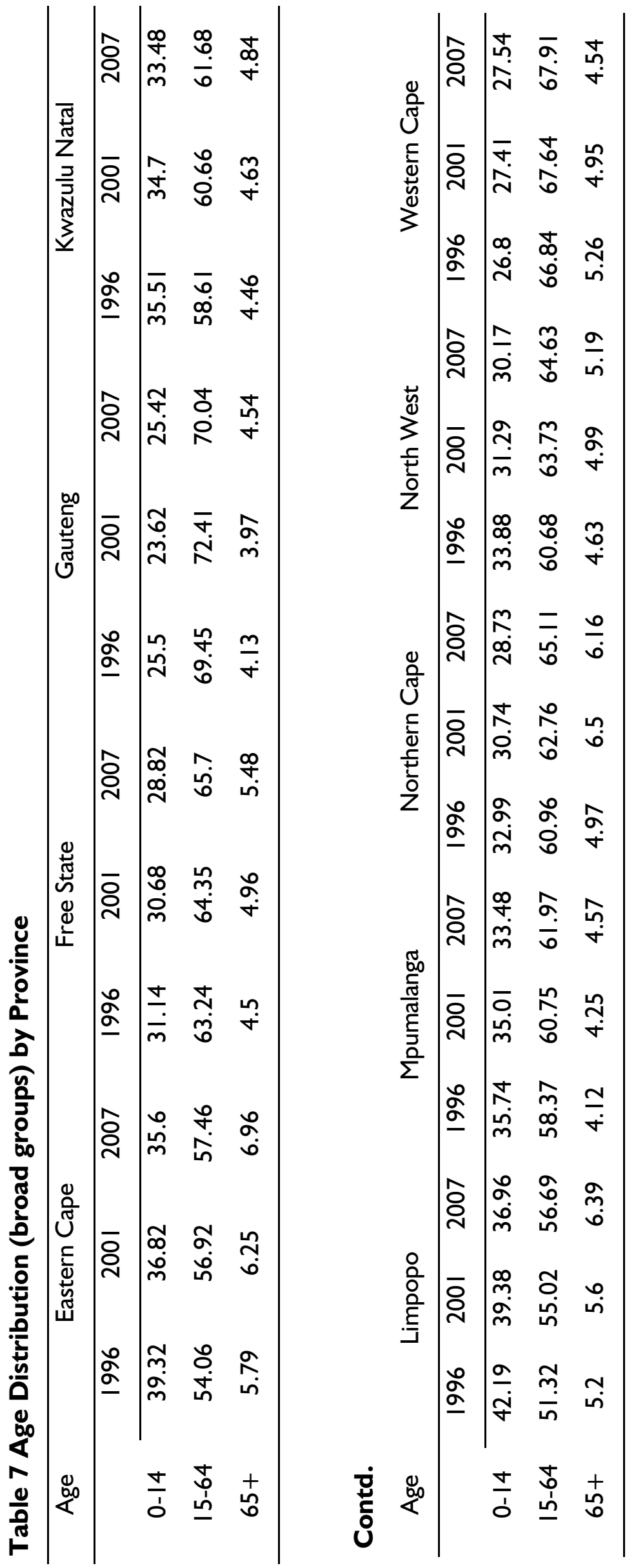


\section{Conclusion}

The age structure is an effective pointer to the development needs of a country at macro level. The influence of age structure on a state's security, political system and development is significant and quantifiable. By and large, the proportions of population under 15 years and above 65 suggest the priority as well as quantum of social investments, especially in education and health, needed in a country. The age structural transition shows the trend and, essentially invokes the so-called 'demographic bonus' or 'window of opportunity' for the national planners mainly due to the reduction in the proportion of young population and increase in labour force population. With this backdrop, let us examine the case South Africa in the following paragraphs.

By and large, the population in South Africa is young. In 2007, 62 percent of males and 58 percent of females were below 30 years. Around one third $(31 \%)$ of the population was enumerated below 15 years of age, 64 percent between 15-64 and 5.4 percent aged $65+$. The total dependency ratio has been quite high, around 57 percent with about 49 percent of young age dependency. Countries with a very young age structure are much more likely to have experienced outbreaks of civil conflict in recent times. Between 1970 and 2007, 80 percent of all new civil conflicts occurred in countries in which 60 percent or more of the population was younger than age 30 . In the same vein, the likelihood of democratic governance increases markedly as countries experiencing AST implying the demographic transition (Daumeri and Madsen, 2010). This calls for con- tinued higher investments on primary and secondary education, health care service delivery and job creation. A young age structure combined with limited opportunities for youth can enable a sense of hopelessness, disenfranchisement toward political leaders and increasing vulnerability to violent conflicts. Again, if the youth are not taken care of from the point of view of education, health and employment, there is potential for political turmoil. Young men sitting unemployed in villages will be easy prey to village elders to egg them on (Daumeri and Madsen, 2010).

Without steady, high rates of job creation, economic prospects worsen over time as the size of the youth cohorts entering the job market steadily grows. From an economic and human perspective, the large number of young people in South Africa's population has the potential to be a tremendous asset, as these individuals will shape the country's future. Here is the relevance of the 'window of opportunity'.

Further, there is a trend in which countries with a very young age structure have a Gender Equity Index score 27 percent lower, on average, than those with a mature age structure. In South Africa the index value is only 20 . This, again, calls for prioritised investments to reduce gender gaps in development strategy.

Nearly two third (64\%) of the population in South Africa is in the labour force age group. This is likely to increase in the near future since fertility is falling in the country. It implies that the country will have an opportunity to reap the benefits of the "demographic dividend' which leads to increased eco- 
nomic well-being at the national and household levels. This presupposes, of course, a steady increase in job creation for the youth cohorts entering into the labour force. In a developed country with labour scarcity, this will be a bonus or opportunity for retaining an enhanced economic growth rate. But, for a country like South Africa where unemployment rate is quite alarming, this enormity of labour force may turn out to be a demographic malus.

One fifth $(20.4 \%)$ of the population is in 15-24 years age group which is the target group for tertiary education. This proportion is also likely to increase at least for the next decade. This calls for sustained higher investment in tertiary education. Of course, the postapartheid South Africa continues to give importance to higher education unlike most of the sub-Saharan countries.

The proportion of the aged $(65+)$ is slightly above 5 percent only implying an early stage of the aging process. However, it is likely to increase steadily for many decades. The tempo of aging is found higher for females as found elsewhere mainly due to the female advantage in life expectancy. It may be noted that the majority of females aged $65+$ would probably be widows. Social and economic security for this disadvantaged group is of prime importance especially among the black population.

Generally, the black population in South Africa appears younger and the whites older; the other two ethnic groups placed in the middle. The proportion of young dependents (0-14 years) is again lowest for Whites followed by Asians \& Indians and Blacks; it is quite high around one third of the population. The dependency ratio is also the highest for Blacks (69 \%) compared to $47 \%$ for Whites. This again warrants for preferential resource allocation for Blacks in the country especially in the areas of reproductive health and employment.

Interestingly, the proportion of economically active population in 2007 is the highest for Asians \& Indians followed by Whites; and the lowest for Blacks. For the whole population, it ranges from 62 to 72 percent. So far as the proportion of the aged segment of the population is concerned, Whites lead comparatively high (12.4\%) in relation with coloured and Black population groups. These imply that the white population is quite aged in comparison with other three ethnic groups in South Africa- a reflection of lower fertility, lower mortality and higher economic status for whites. The dependency rates are also higher for Black population and lesser for Whites and Asians \& Indians.

So far as the provincial age structures in 2007 are concerned, there is tremendous variation across the provinces. Gauteng has the highest Median age (28.2 years) and Limpopo the lowest (20.1 years). Dependency ratios also show the same tendency; 42 percent for Gauteng and 76 percent for Limpopo. This calls for the need for differential developmental efforts at subnational or provincial levels in the country. Provinces such as Limpopo and Eastern Cape need priority in development planning.

During 1996-2007, the age structural transition (AST) observed for the total population is only marginal in South Africa. The median age of the total population grew from 23 years to 
24.3 years, an increase of 5.6 percent only. If we examine the transition of broad age groups, the young age population ( 0 - 14 years) has declined by 8 per cent for the total population; with a slightly more reduction of female children. The old age population has increased by 12.5 percent during the same period along with the global trend of female advantage. Again, the labour force population has increased by 5.5 percent. These imply that the irreversible and inevitable window opportunity invoked by AST, as mentioned earlier, is on the increase in South Africa and the challenges posed by it in development planning have to be dealt with effectively. Otherwise, the socio-economic and even political consequences would be, perhaps, disastrous.

\section{References}

Chimere-Dan, O (1993). Population Policy in South Africa. Studies in Family Planning, No. 24, pp. 3I-39, New York.

Daumerie, B and E.L. Madsen ( 2010)
The effects of a very young age structure in Uganda : Country case study. The Shape of Things to come series, Population Action International, Washington.

Majelantle R.G and P. Sadasivan Nair ( 2007) "Levels and Trends in Infant and Child Mortality in Botswana", JANASAMKHYA, Vol. XXI, Pp 7585, Department of Demography, University of Kerala, India. Pp.75-85.

P. Sadasivan Nair and R.G. Majelantle ( 2005) "Age Structural Transition in Botswana, I97I-200I", JANASAMKHYA, Vol. XX, Pp 2I-3I, Department of Demography, University of Kerala, India. Pp. 2I-3I.

Nair, P. Sadasivan (2010), Population Aging in Botswana: Trends and Implications, Journal of African Studies and Development, Vol. 2 (4).

Swartz, Leon (n.d), Fertility Transition in South Africa and its implications on the four major population groups, http://www.un.org/esa/ population/publications/. 